\title{
La escultura arquitectónica modelada en estuco de Calakmul, Campeche, México: la transformación material en el proceso tecnológico
}

Stucco Architectural Sculpture from Calakmul, Campeche, Mexico: Material Transformation Throughout the Technological Process

Claudia A. García Solís

Universidad Autónoma de Yucatán (UAdY), México

clausoldia@gmail.com

Demetrio Mendoza Anaya

Instituto Nacional de Investigaciones Nucleares (ININ),

Secretaría de Energía (SENER), México

demetrio.mendoza@inin.gob.mx

\section{Patricia Quintana Owen}

Departamento de Física Aplicada,

Centro de Investigación y de Estudios Avanzados (Cinvestav), Instituto Politécnico Nacional (IPN), Mérida, Yucatán, México pquint@cinvestav.mx

\section{Resumen}

La escultura arquitectónica elaborada en estuco del friso de la estructura Sub IIC-1 del sitio arqueológico de Calakmul, Campeche, México, constituye un caso de estudio paradigmático para entender los orígenes de una urbe que se convirtió en una de las capitales regionales más destacadas de la cultura Maya de las Tierras Bajas. En particular, la caracterización de los materiales y de las técnicas empleadas en cada una de las etapas de elaboración de este relieve escultórico demuestra que la especialización en la manufactura deriva tanto de un conocimiento pleno sobre la explotación local de la materia prima como de una tradición tecnológica compartida con otros sitios Preclásicos de la región del Petén.

\section{Palabras clave}

tecnología; Calakmul; argamasas de cal; especialización; preclásico; maya

\section{Abstract}

The stucco architectural sculpture of the frieze of the structure Sub IIc-1 of the archaeological site of Calakmul, Campeche, México, is a paradigmatic case study for understanding the origins of a city that became a regional capital of the Maya Lowlands. In particular, the identification of materials and techniques of each of the stages for the construction of this relief demonstrate that 
craft specialization derived from both the knowledge on the local exploitation of materials and a technological tradition shared with other Pre-Classic sites of the Peten region.

\section{Key words}

technology; Calakmul; lime mortars; stucco sculpture; specialization; Pre-classic; Maya

\section{Introducción}

a producción de un artefacto, cualquiera que éste sea, requiere una secuencia de operaciones, o chấne opératoire, que inicia con la adquisición de la materia prima y finaliza con la realización del bien (cfr. Leroi-Gourhan 1964). Este proceso no sólo exige una destreza manual de las personas involucradas en la manufactura, sino que también es indisoluble del proceso cognitivo del saber-hacer, del conocimiento de las características de los materiales que se transforman (cfr. Pelegrin et al. 1998; Ingold 2001), y de las prácticas socio-simbólicas de su cultura (cfr. Dobres 2000; Schiffer 2004). Aun así, el desarrollo de cierto tipo de tecnología también está directamente relacionado con el tipo de materias primas accesibles en el entorno natural donde se han establecido determinadas sociedades. En Mesoamérica, algunos sitios se vieron beneficiados por la explotación de fuentes de materiales que eran abundantes en su medio natural, así como escasos en otras regiones: tal es el caso de la obsidiana en Teotihuacan (cfr. Braswell 2003). Otro ejemplo notable es el empleo de la piedra caliza y sus derivados en el área maya, materiales que dieron forma y significado a mucha de su arquitectura.

Calakmul —sitio localizado en la microrregión del Petén campechano, en las denominadas Tierras Bajas Mayas, y con una cronología estimada entre el 600 a.C.-900 d.C - no es la excepción. Al contrario, esta urbe constituye un interesante caso de estudio tecnológico. Una reciente disertación de Geovannini Acuña (2008) demostró que, ante un escaso abastecimiento de agua, los habitantes de Calakmul subsistieron gracias a una adecuada explotación silvícola, combinada con una administración racional de la agricultura de temporal. Notablemente, dicha restricción de agua, tan necesaria para la producción de cal, tampoco les significó un obstáculo para que en Calakmul se hiciere un uso extensivo de grandes volúmenes de estuco en la arquitectura más temprana del sitio. Ejemplo de ello es el relieve de estuco del friso de la estructura Sub IIC-1 (Figura 1) el cual representa un proceso innovador de adaptación de los recursos existentes, cuyos inicios pueden trazarse en la región del Mirador durante finales del Preclásico Medio (Hansen et al. 1995).

El descubrimiento del relieve de estuco de la Sub IIC-1 se remonta al 2001, año en el que el Proyecto Arqueológico Calakmul (PAC), del Instituto Nacional de Antropología e Historia (INAH, México), dirigido por el arqueólogo

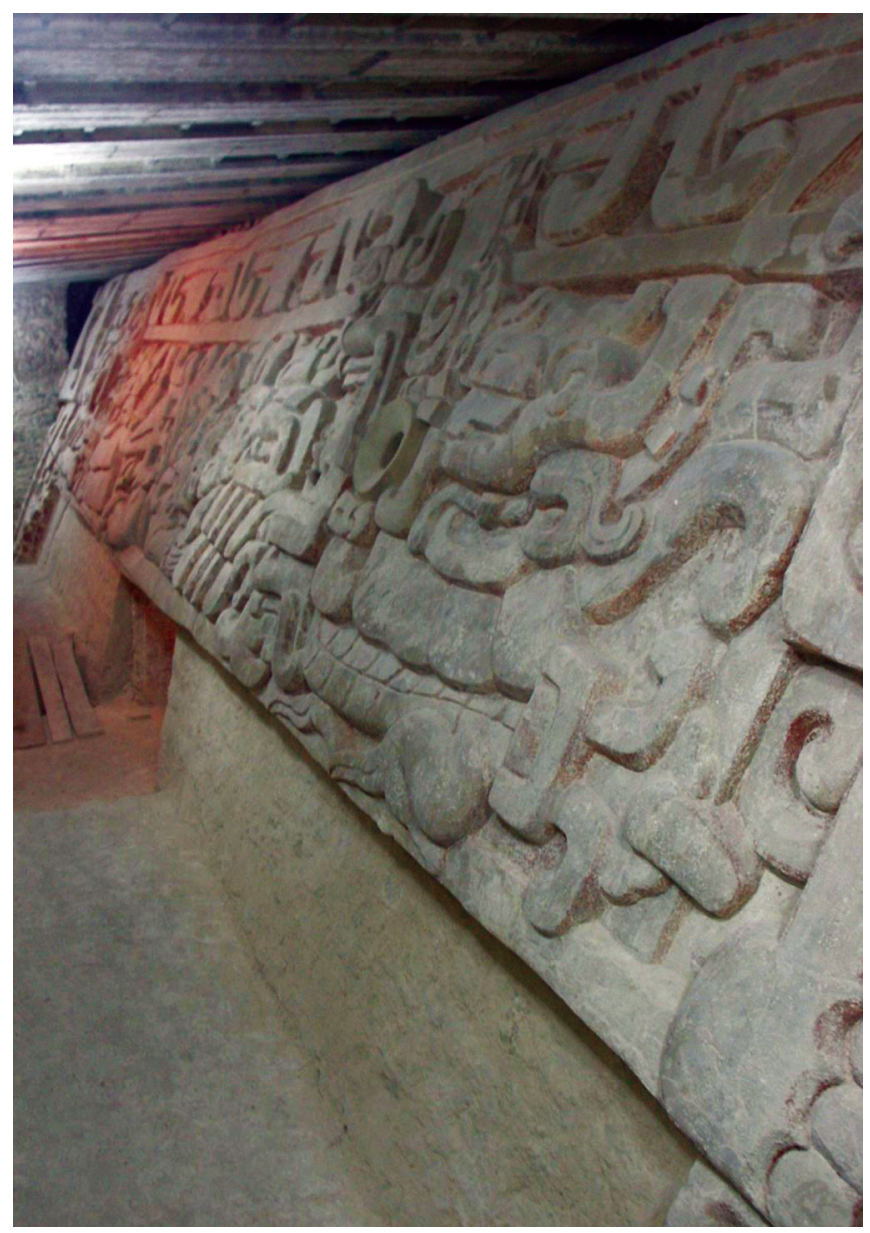

FIGURA 1. Vista lateral del relieve de estuco del friso de la estructura Sub IIC-1 del sitio arqueológico de Calakmul, Campeche (Fotografía: Omar Rodríguez; fuente: García, 2011, cortesía: INAH).

Ramón Carrasco, encontró en el interior de la Estructura II un conjunto arquitectónico datado para finales del Pre-clásico Medio e inicio del Pre-clásico Tardío (390-150 a.C.), ${ }^{1}$ el cual presentaba sendos relieves y acabados de estuco adosados (Carrasco y Colón 2005:41). En el transcurso del proceso de excavación de la subestructura principal denominada Sub IIC-1-, se integró un proyecto de conservación específicamente enfocado en la recuperación y estabilización del modelado en estuco que aporta la iconografía de su fachada principal (cfr. García 2011). De dicho proyecto surgió una investigación sobre la secuencia de operaciones y organización implicada en la factura del relieve, estudio que se basó tanto en observaciones en campo como en la aplicación de diversas técnicas analíticas: petrografía, difracción de rayos X (DRX

\footnotetext{
${ }^{1}$ Estos rangos se basan en fechamiento absoluto de radiocarbono: para la Sub Ilc-1 se prefiere utilizar la fecha más temprana de 390 a. C., al considerar la secuencia arquitectónica de la Estructura II (Rodríguez 2008:14). Sin embargo, la cerámica de los pozos confirmaría que el friso se sitúa en el complejo Zihal del Preclásico Tardío (300 a. C.-150 d. C.) (García 2011:174-179).
} 
[XRD] por sus siglas en inglés), microscopia electrónica de barrido acoplada con fluorescencia de rayos $\mathrm{X}$ por energía dispersiva (MEB-EDS [SEM], por sus siglas en inglés), microscopia óptica (MO [OM], por sus siglas en inglés), así como pruebas físicas de compresión, densidad y porosidad. Los resultados constituyen el centro de esta contribución. $^{2}$

Es de notar que existe un cuerpo germinal de literatura dedicado a las técnicas de modelado en estuco en sitios del área maya, entre los que destacan Palenque (cfr. Greene 1987; Vázquez del Mercado y Villegas 1993) y Toniná (cfr. Mateos 1997), ambos en Chiapas y Kohunlich, Quintana Roo (cfr. Zetina 2007), todos en México. En conjunto, estos trabajos aportan importantes referencias técnicas y materiales para establecer similitudes y diferencias entre sus casos y el que aquí se analiza. Asimismo, entre las investigaciones arqueométricas de argamasas, pisos y relieves adosados a arquitectura Maya sobresalen las de Hansen et al. (1995) y Hansen y Rodríguez-Navarro (2002) para Nakbé; Straulino et al. (2013) y Gillot (2014) para Río Bec y Dzibanché, y el comparativo regional, basado en petrografía, de diversos sitios arqueológicos mayas por Villaseñor (2008, 2010), que incluye muestras de Calakmul. Es de subrayar que la primera publicación de esta última autora (Villaseñor 2008:132) identificó un comportamiento hidráulico en las pastas de mortero de estuco que conforman los pisos de este sitio, mismo que sugiere la integración de cenizas volcánicas en su composición.

La presente investigación incorpora información derivada de estos estudios tecnológicos del área maya en comparativo con el análisis de manufactura del friso de la fachada de Sub IIC-1 de Calakmul con la finalidad de sustentar que las características excepcionales de este último relieve obedecieron a un proceso de creatividad e innovación tecnológica fundado en el conocimiento del uso de materiales locales y la especialización de actividades que compartió el Petén del Preclásico.

\section{Del proceso tecnológico y sus fases}

El estudio del proceso tecnológico se divide en cinco momentos que corresponden a las fases o estratos de factura del friso.

\section{Soporte de piedra}

Con vistas al posterior modelado en estuco, el soporte del friso de la fachada norte de la Sub IIc-1 se construyó con una combinación de sillares y relieves labrados en piedra caliza, unidos con argamasa elaborada con mortero de

\footnotetext{
${ }^{2}$ Todas las muestras para los diferentes análisis fueron obtenidas de los fragmentos de estuco desprendidos que no pudieron reubicarse durante los procesos de conservación y restauración. La mayor concentración de zonas de desprendimiento se ubican en la parte superior del friso.
}

cal y arena. El arreglo en piedra generó, además de un patrón en el friso, las molduras y los elementos labrados en piedra del mosaico, un marco para la distribución y el diseño de formas complejas (Figura 2).

El concepto y la resolución tecnológica de este soporte son comparables al de los mosaicos de piedra de las portadas zoomorfas del área Río Bec, siendo la más conocida la de la Estructura II de Chicanná. Como lo describen García Solís y Valencia Pulido (1997:50), los altorrelieves de piedra de este último caso surgen de uno o varios prismas que, de forma rectangular o cuadrada, conservan una geometría de fondo para poder ajustarse entre sí. Así, aunque algunos motivos no se labraron con formas especiales - su diseño se hizo a partir de la agrupación y el acomodo de sillares de distintos tamaños en niveles y posiciones diferentes-, otros de los elementos proyectados, como los colmillos de las fauces alrededor de los vanos de acceso, poseen, empotrados en el relleno constructivo, largas espigas de tamaño proporcional a su proyección (García y Valencia 1997:54).

Aunque el soporte del friso de la Sub IIc-1 de Calakmul también es mosaico debido a la combinación de siIlares y elementos labrados, éste, en lugar de tratarse de un muro recto, guarda cierta inclinación. Gracias a ello, se empotraron piedras de mayor dimensión que permitieron labrar formas completas, particularmente notables en las volutas en forma de J o en las orejeras de las aves. Sin embargo, según las observaciones de campo, las únicas piezas que poseen grandes espigas son las piedras de la cornisa, por ser éstas las que inician el talud.

Como resultado del estudio petrográfico (Figura 3), podemos proponer que la piedra utilizada en la construcción de los muros y el soporte del friso de la Sub IIC-1 de Calakmul debió provenir de una cantera que corresponde a una facie estrato de calizas puras formada por la cementación de lodos calcáreos y de bioclastos marinos, tal como se identificó en las propias cercanías de la Estructura I. La baja consistencia y la dureza (Figura 5) de este tipo de material debieron haber contribuido, desde su extracción en la cantera, a obtener de manera rápida las formas del relieve y a ajustar los cortes durante el montaje.

Ahora bien, a diferencia de los mosaicos de Chicanná, en el relieve de la Sub IIC-1 de Calakmul no parece haberse tenido la intención de hacer formas detalladas mediante el tallado de sustrato rocoso, ya que los volúmenes se generarían con el modelado de estuco. Notablemente, las superficies del soporte pétreo se dejaron lisas, lo que es contrario a lo sucedido en Palenque donde los bloques de piedra conservaron la textura rugosa que facilitó un buen anclaje con el recubrimiento de estuco (Vázquez del Mercado y Villegas 1993:63). Por ello, uno de los efectos comunes de alteración de nuestro caso de estudio es el desprendimiento del estuco con respecto al soporte de la piedra. 


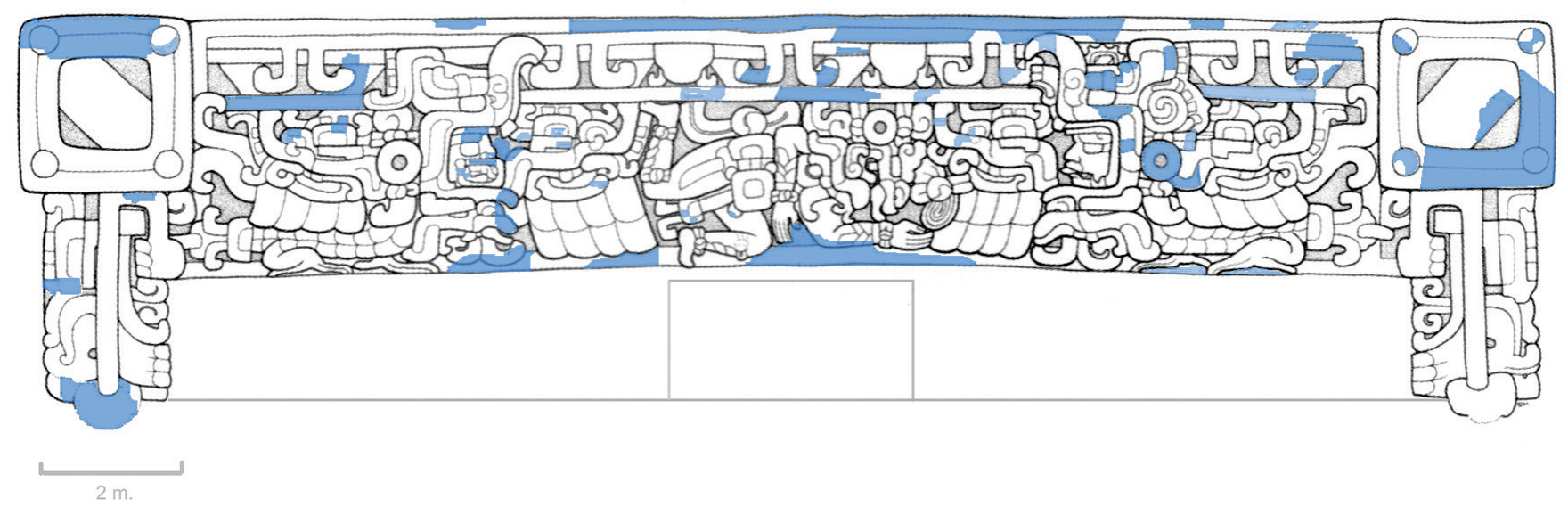

FIGURA 2. Esquema del relieve de estuco de la Sub IIC-1 del sitio arqueológico de Calakmul, Campeche, en donde se ubican, en color azul, las formas labradas en piedra del mosaico de soporte que fueron identificadas en campo (Dibujo: Simon Martín; fuente: Carrasco 2005:64; registro modificado: Claudia A. García Solís, 2002; cortesía: INAH).
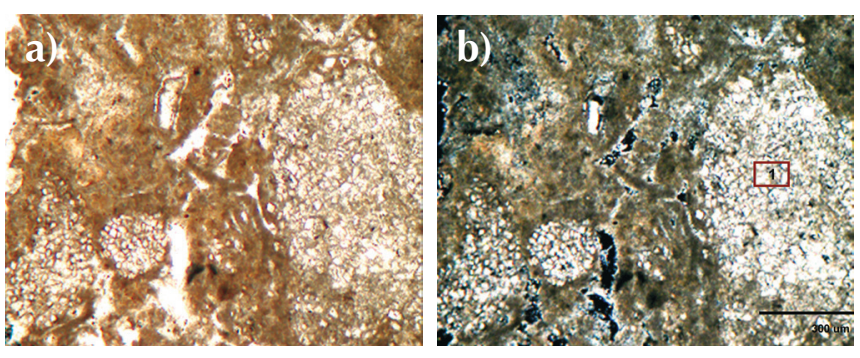

FIGURA 3. Imágenes petrográficas de la piedra utilizada en el soporte del relieve de estuco de la Sub Ilc-1 de Calakmul: a) luz paralela; b) nicoles cruzados. El estudio muestra que la roca se originó por la deposición de bioclastos (73\%), principalmente algas y moluscos, cementados por un lodo calcáreo (micrita). En este ejemplo, los bioesqueletos de aragonita fueron reemplazados parcialmente por microesparita (cristales visibles) y micrita. Véase [1]: la zona concentrada de microesparita, en sustitución de un resto fósil de un alga (Fotografía: Petroanálisis ${ }^{\circledR}$, 2006; fuente: García, 2011:187; cortesía: INAH).

\section{Aplanado}

Una vez concluido el mosaico de piedra del talud del friso de la Sub IIC-1 de Calakmul, se continuó con la aplicación de un aplanado (Figura 4), cuyas principales funciones fueron ocultar las irregularidades del muro inclinado

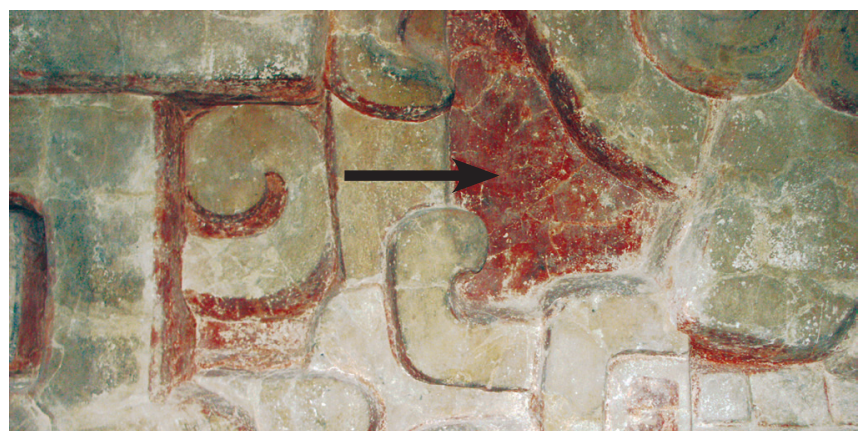

FIGURA 4. Muestra de una sección del relieve del friso de estuco de la Sub IIC-1 de Calakmul: la flecha señala al aplanado de fondo pintado de color rojo (Fotografía: Claudia A. García Solís, 2004; fuente: García, 2011, cortesía: INAH).

\begin{tabular}{|c|c|c|c|c|c|}
\hline $\begin{array}{l}\text { Propiedades } \\
\text { físicas y de } \\
\text { resistencia }\end{array}$ & $\begin{array}{l}\text { Calizas } \\
\text { (Oates } \\
1998)\end{array}$ & $\begin{array}{l}\text { Relieves de } \\
\text { El Tigre } \\
\text { (Vargas } \\
\text { 2007) }\end{array}$ & $\begin{array}{c}\text { Piedra } \\
\text { de soporte } \\
\text { de muro }\end{array}$ & $\begin{array}{l}\text { Piedra de } \\
\text { soporte } \\
\text { del friso }\end{array}$ & Relieve \\
\hline $\begin{array}{l}\text { Peso } \\
\text { volumétrico } \\
\text { seco }\left(\mathrm{g} / \mathrm{cm}^{3}\right)\end{array}$ & & & 1.90 & 1.32 & 1.46 \\
\hline $\begin{array}{l}\text { Densidad } \\
\text { Aparente } \\
\left(\mathrm{g} / \mathrm{cm}^{3}\right)\end{array}$ & & $1.38 / 1.70$ & 2.18 & 1.75 & 1.87 \\
\hline $\begin{array}{l}\text { Densidad } \\
\text { relativa ss } \\
\left(\mathrm{g} / \mathrm{cm}^{3}\right)\end{array}$ & $\begin{array}{c}1.5 \text { a } 2.3 \\
\text { creta } \\
2.7 \text { cali- } \\
\text { zas densas } \\
2.7 \text { a } 2.9 \\
\text { dolomitas }\end{array}$ & & 2.56 & 2.29 & 2.32 \\
\hline Absorción & & & 12.66 & 31.7 & 22.3 \\
\hline Porosidad (\%) & $\begin{array}{c}0.1 \text { a } 2 \\
\text { mármol } \\
0.1 \text { a } 30 \\
\text { calizas } \\
15 \text { a } 40 \\
\text { cretas } \\
<50 \% \\
\text { marls }\end{array}$ & $30.9 / 42.7$ & 24.3 & 41.77 & 34.09 \\
\hline $\begin{array}{l}\text { Resistencia a la } \\
\text { compresión } \\
\left(\mathrm{kg} / \mathrm{cm}^{2}\right)\end{array}$ & & & 156 & 32 & 23 \\
\hline
\end{tabular}

FIGURA 5. Resultados de análisis de dureza, porosidad y compresión de las piedras del mosaico y relieves del friso con referentes de comparación (Cuadro: Claudia A. García Solís; fuente: García Solís, 2011:220; cortesía: INAH). 
de soporte, servir de lienzo para la realización de gran parte del dibujo preparatorio donde se adosa el primer nivel de elementos y constituir el fondo del relieve.

Debido a los amplios espacios entre las formas labradas o proyectadas del soporte fue posible manipular las pastas de cal al punto de dejar una superficie alisada de poco grosor, proceso que implicó la compactación de material en tanto generó una presión homogénea con una superficie lisa.

Sobre este aplanado liso se pintó el dibujo preparatorio que serviría de guía para el modelado y la integración de las aplicaciones de estuco, el cual denominamos sinopia. Asimismo, luego de delimitar los volúmenes de estuco con el dibujo, este aplanado también se pintó de color rojo para servir de fondo, un tratamiento que se hace evidente por la ausencia de color justo en las áreas donde se ha desprendido el alto-relieve modelado.

\section{Sinopia}

Se denomina sinopia al esquema general de la composición mural realizada in situ, normalmente sobre un aplanado medio (Mora et al. 1984:13). En el caso del estuco de la Sub IIC-1, la sinopia —un trazo de color rojo sobre el aplanado de fondo y formas pintadas sobre los relievesse identificó solamente en las áreas donde se desprendieron los relieves y sobre el soporte de piedra (Figura 6).

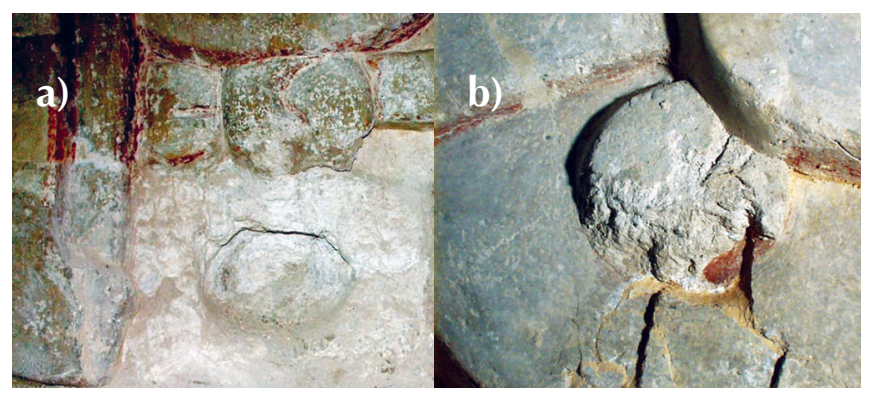

FIGURA 6. Sinopia de color rojo: a) línea delimitando las zonas donde se extiende el modelado directo y b) forma pintada de rojo para identificar los detalles y marcar zonas de aplicación (Fotografía: Claudia A. García Solís, 2002; fuente: García, 2011, cortesía: INAH).

Como se explicó anteriormente, el diseño integral del friso inició con los elementos labrados en piedra, para después integrarse sobre el aplanado del fondo con el dibujo de trazos libres. Tal y como se observa en la orejera, la línea del boceto sirvió de guía para constituir el volumen de estuco (Figura 6a). En diversos relieves de estuco de Palenque, así como en el de los Cuatro Soles de Toniná se han identificado secuencias operatorias similares, pero en trazo negro (Vázquez del Mercado y Villegas 1993:6061; Mateos 1997:47).

En el caso del relieve de la Sub IIC-1 de Calakmul se ha precisado que, además de una voluta pintada (Figura $6 b)$, varios fragmentos desprendidos tenían una colora- ción roja en su parte posterior. Esto hace pensar en que varias formas de la sinopia no sólo se trazaron en línea sino se iluminaron en su forma interior principalmente con el objeto de señalar dónde se ubicarían las formas previstas. Al adosar los relieves, la pintura quedó atrapada en los morteros aún frescos.

Nuestras observaciones también indican que para apreciar la composición completa, los artífices requirieron evidenciar el diseño tanto en las diferentes etapas del proceso de modelado como en cada nivel de aplicación de elementos. Así, como ya se ha explicado, con base en las líneas del boceto se delimitaron las formas de volumen y el resto del aplanado se pintó de color rojo para funcionar como fondo. Con ello, las áreas donde se debían modelar los volúmenes de estuco quedaron visibles en negativo, mientras que en las áreas del relieve se dibujaron, también de color rojo para contrastar con el fondo, las formas completas.

No hemos logrado una explicación técnica convincente para explicar la presencia de color rojo en las formas labradas en piedra - como aquella correspondiente al soporte que forma las grandes orejeras rectangulares de los extremos superiores-. En efecto, la dimensión de esos elementos y su evidente forma no parecen haber requerido que se pintara diseño alguno para servir de guía para el recubrimiento de estuco. Así que con base en evidencia, postulamos que la elaboración de un dibujo preparatorio no sólo constituye un proceso creativo que supone una jerarquización de actividades sino que también constituye una acción de carácter ritual, tal y como lo plantea García Solís (2011:271-272).

\section{Relieve}

Técnicamente, el friso es un alto-relieve: aunque el diseño está limitado por un marco por una zona superior de colmillos y por serpientes laterales (Figuras 1 y 2), los límites de su proyección de sus formas se expanden a través de un juego de volúmenes. Además de cumplir un propósito plástico, este manejo de planos enfatiza el significado de la composición ya que centra la atención en las figuras principales, como es el personaje central y las aves-reptil con rostros humanos.

Lograr la proyección de las representaciones del friso constituyó un reto técnico de diversas magnitudes, ya que implicó tanto el libre manejo del modelado de grandes volúmenes de estuco como la superposición de hasta cuatro niveles de formas; un efecto que permitió dejar en un segundo plano el esquema simétrico del mosaico de piedra, así como las regularidades derivadas de su propia ejecución (Figura 7).

Con base en las observaciones de campo, planteamos que los volúmenes de argamasa de cal se aplicaron de dos formas: modelado directo y colocación de formas pre-modeladas. El primero se observa en las figuras principales y en algunos elementos de las formas labradas del 


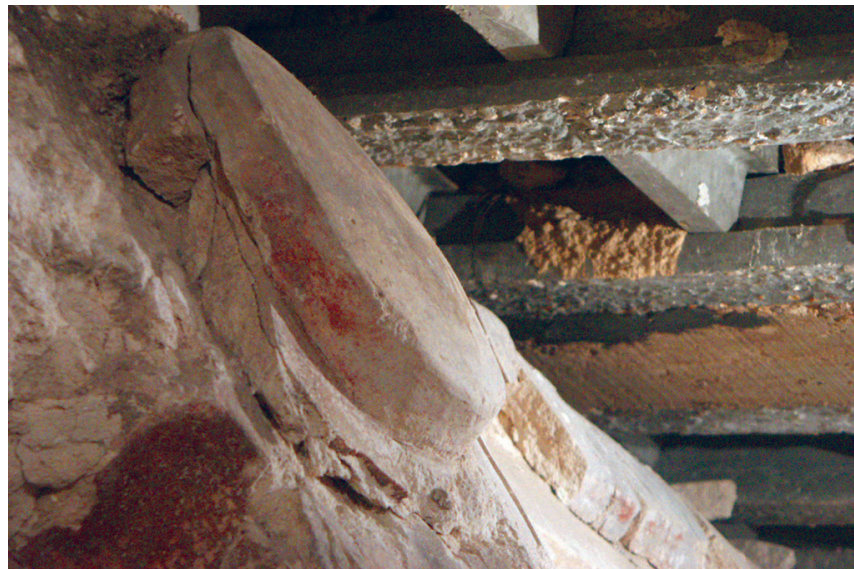

FIGURA 7. Voluta modelada en estuco, cuyo desprendimiento muestra que se aplicó sobre un primer nivel de recubrimiento una vez modelada (Fotografía: Claudia A. García Solís, 2002; fuente: García, 2011, cortesía: INAH)

mosaico de piedra. En cambio, las formas pre-modeladas complementan tanto el diseño en los distintos niveles ( $\mathrm{Fi}$ gura 7) como, con algunas variantes, la manipulación de placas para la integración de los recubrimientos que cubren las molduras. Desde nuestro punto de vista, la aplicación particular de formas y placas es comparable con el manejo de pastas de arcillas en la producción de cerámica (cfr. Caro Bellido 2008:33).

El desprendimiento de elementos enteros o por secciones sugiere que las aplicaciones se integraron sobre las principales figuras (Figura 7), dando forma, así, a los diferentes niveles del friso, según se ha visto en varios otros ejemplos de Palenque (Greene 1987:30), Toniná (Mateos 1997:37-40) y Kohunlich (Zetina 2007:232). No obstante, a diferencia de los anteriores, el friso de Calakmul carece de una preparación previa en la superficie - aumento de textura- para optimizar el anclaje de los añadidos. ${ }^{3}$ No descartamos la posibilidad del uso de algún tipo de adhesivo para favorecer la unión de formas en un sustrato alisado. Un indicador de ello son las sutiles huellas de las formas desprendidas del aplanado que presentan un tono más saturado en superficie, mismo que podría estar relacionado con la presencia de un material orgánico que no fue necesariamente aplicado de manera directa, sino que pudo proceder del enriquecimiento de las pastas con aditivos de corteza, como se han utilizado tradicionalmente en el área maya (cfr. García y Jáidar 2013). Sin embargo, esta suposición tendría que corroborarse con análisis específicos para materiales orgánicos.

\footnotetext{
${ }^{3}$ Esta preparación del sustrato sólo se identificó en un sólo caso: la sección del nudo de la pierna del personaje principal, en el que la superficie del relieve está picada. Sin embargo, consideramos que este tratamiento es excepcional, por varios motivos: éste fue el único elemento que no se encontró in situ, ya sea desprendido del soporte o mezclado en el relleno, y el fragmento aún adherido tenía bordes redondeados por abrasión. Por ello, planteamos que posiblemente nos encontramos ante la evidencia de una reparación prehispánica.
}

Adicionalmente, debido a la homogeneidad de su gran espesor (10 cm aproximadamente) y al patrón de su desprendimiento, proponemos que los recubrimientos de las molduras pudieron haberse realizado mediante la distribución de placas compactas de estuco sobre grandes secciones cuando los morteros se encontraban aún en estado plástico.

Es de notar que la buena consistencia y dureza del estuco, que llega a exceder en densidad a la de las mismas piedras del soporte (Figura 5), deriva de la composición de la cal, del uso de una granulometría variada de cargas en el mortero y así como una correcta distribución de texturas, según se observa en las láminas petrográficas (Figura 9) y micrografías de la MEB (Figura 10). Los resultados de los análisis del DRX (García et al. 2006) corroboran que los lodos calcáreos tienen un alto porcentaje de carbonato de calcio. Si se considera el uso de una sola fuente para la obtención de materiales constructivos en Calakmul, ${ }^{4}$ las mismas calcitas excepcionalmente puras del soporte del friso se utilizaron para la fabricación de cal.

Las calizas de alta pureza producen cales grasas de fácil manejo y con mayor probabilidad de lograr un buen fraguado con un secado controlado (Boyton 1966:9). De acuerdo a los análisis por DRX (García et al. 2006), los morteros empleados en la unión de los sillares del talud y en los relieves son, básicamente, calcita con presencia de trazas de illita, aragonita y sílice (Figura 8).

\begin{tabular}{|c|c|c|c|}
\hline \multicolumn{2}{|c|}{ Tabla resumen de los materiales relacionados a la manufactura del friso por } \\
DRX (García et al. 2006)
\end{tabular}

FIGURA 8. Resultados obtenidos por DRX de los principales materiales constitutivos del relieve de estuco de la Sub Ilc-1 de Calakmul (Fuente: García et al 2006:249; cortesía: Cinvestav-Mérida).

${ }^{4}$ La secuencia geológica de Calakmul se forma de: caliza y dolomía con horizontes arcillosos que ocasionalmente llegan a presentar fragmentos de pedernal en alternancia con depósitos de yeso (Castro-Mora 2002:43). 
Al comparar los resultados de la composición de las calizas que forman los sillares de la estructura Sub IlC-1 con los respectivos a sus morteros (Figura 8) se hace evidente que, algunos minerales fueron agregados a las pastas, la aragonita proviene del uso de saskab. ${ }^{5}$ Otros materiales, alternativamente, sufrieron transformaciones durante el proceso de la quema de la cal: tal es el caso de la montmorillonita que está presente en las piedras del soporte y que a causa del alza de temperatura debió perder su estructura para reconvertirse en illita, un proceso ya descrito por Hansen y Rodríguez-Navarro (2002:185). Adicionalmente en las láminas petrográficas se observa que los materiales de textura fina, plenamente integrados en el mortero, se distinguen en la superficie de acabado con un grosor de apenas $0.5 \mathrm{~mm}$ (Figura 9).

Cabe subrayar que la mezcla en los morteros fue determinante para lograr amplios volúmenes de gran dureza y buena consistencia en los elementos modelados en el friso de estuco. En efecto, el uso de cales de alto contenido de calcita garantiza una buena cementación, siempre y cuando se añadan proporciones adecuadas de agregados pétreos y agua, tal y como se puede revisar en las láminas petrográficas del relieve aquí bajo estudio (Figura 9) que muestran que las cargas de las matrices tienen una granulometría variada y formas diferentes. Es notable, asimismo, que los agregados varíen en composición, ya que es posible distinguir hasta cinco tipos de calizas. El sascab, dada su degradación natural, por lo general presenta bordes de subredondeados a redondeados; sin embargo, en las imágenes derivadas de la petrografía (Figura 9) también se distinguen, en menor proporción, partículas angulosas que podrían acaso corresponder a piedra molida de los remanentes del trabajo de cantería.

Ahora bien, nuestro estudio sugiere que una proporción mayor de cargas y la diversidad granulométrica ayudaron a la compactación de las pastas al momento de aplicarlas. Aunque también se considera que el secado del estuco debió de ser controlado, ${ }^{6}$ lo cual derivó en una buena cementación entre partículas. Es de notar que la variabilidad de granos en las cargas, también detectada por MEB (Figura 10), contribuyó a generar un mortero más resistente en el caso que nos ocupa, ello por razón de la reducción en la contracción de la cal al perder agua, especialmente cuando las proporciones de cargas llegan a triplicar el cementante (Magaloni 1996:202). Asimismo

\footnotetext{
${ }^{5}$ Saskab, o sahkab, de acuerdo al diccionario Maya-Yucateco Cordemex (Vázquez 1993), es una piedra deleznable que se usa para preparar mezclas para la construcción. Desde un punto de vista geológico el saskab es el nombre genérico de los estratos de calizas no consolidados o degradados cuya composición varía dependiendo de la geología de la región (Littman 1958).

${ }^{6}$ Aunque en este estudio no fue posible corroborar la presencia de aditivos, el control del secado pudo darse por la incorporación de aditivos orgánicos solubles en agua, que hacen que la evaporación de agua de los morteros sea más lenta (cfr. Magaloni 2001:196).
}

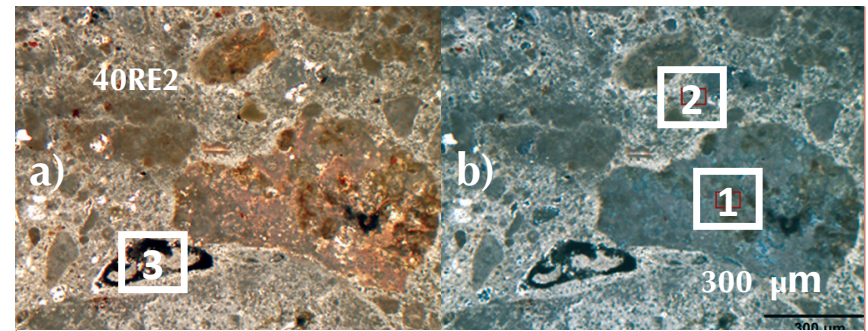

1

Esta muestra es un ejemplo de la constitución de las matrices del relieve del friso: se observa en la mezcla una buena distribución de cargas, a pesar del amplio rango del tamaño de sus partículas sub-redondeadas y angulosas. Morfológicamente, las cargas derivan de cuatro tipos distintos de calizas; en algunas, sus materiales constitutivos han sido alterados, por lo que se observan productos de oxidación de Fe [1]. La matriz calcárea (25\%) es microcristalina parcialmente recristalizada con fragmentos de cuarzo dispersos. En la matriz se observan zonas más opacas [2] o densas que corresponden a material de tamaño de arcilla; en este caso, a las zonas puras de micrita. Este agregado es un fragmento de carbón [3].

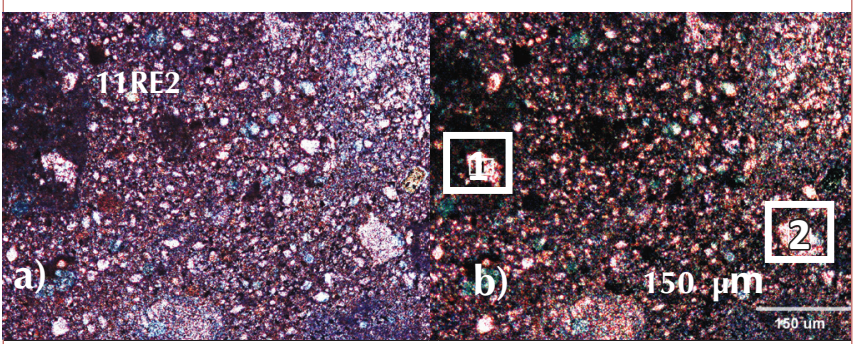

2

Acercamiento de la matriz calcárea donde se aprecia con mayor detalle la mezcla consistente de la micrita y microesparita. La microesparita se distingue a manera de pequeños cristales repartidos homogéneamente, salvo en los casos donde se concentran, ya sea los espacios vacíos de las cargas [1] o en la matriz [2]. Se considera que la esparita forma parte de un proceso de recristalización de la micrita producida durante el fraguado de la cal. La variada tonalidad de colores en la matriz es típica de la birrefringencia de la calcita cuando incide un haz de luz.

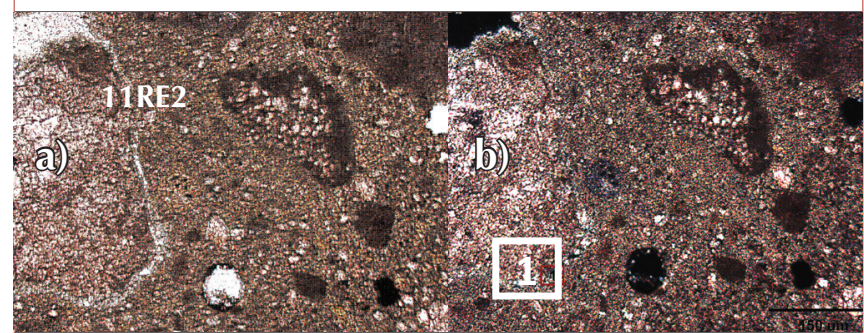

3

Aquí se observa como la microesparita [1] rodea por completo un lítico de las cargas, lo cual confirma que las argamasas que forman el sustrato de los relieves lograron una buena cementación.

FIGURA 9. Imágenes petrográficas del relieve del friso de la Sub IIC-1 de Calakmul: a) luz paralela; b) nicoles cruzados. (Fotografía: Petroanálisis $^{\circledR}$ e Instituto de Geología-UNAM; fuente: García 2011:226; cortesía: INAH). 

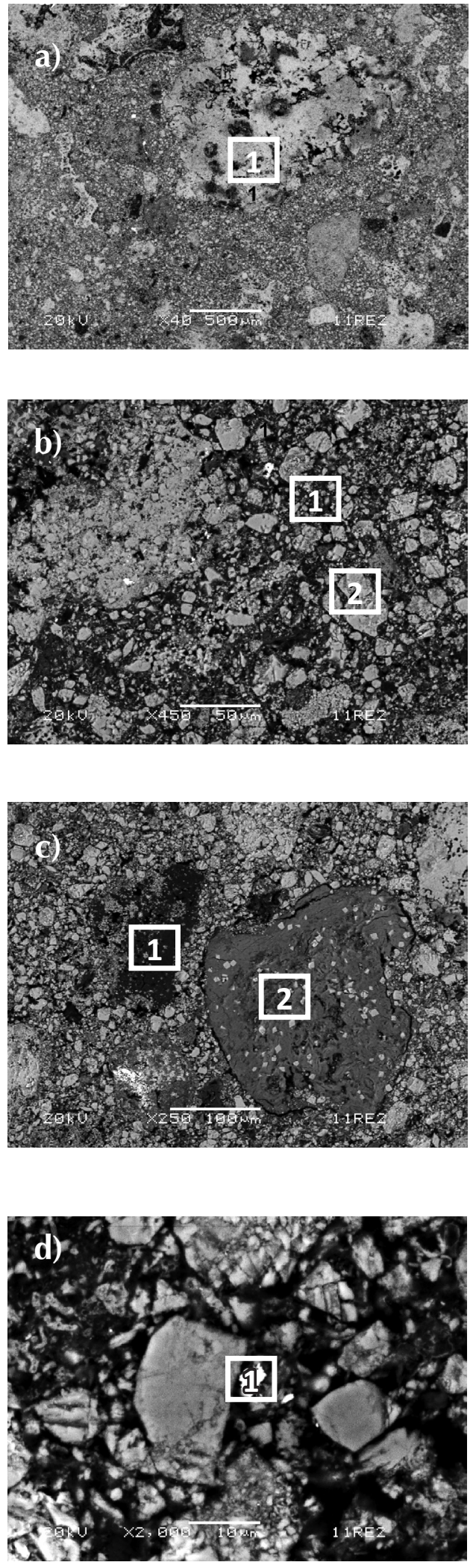

En esta imagen aumentada del mortero, identificamos nuevamente los romboedros de los cristales de calcita de diferente tamaño; algunos mejor formados que otros. La cristalización no forma una unidad sólida, ya que en algunas zonas quedan espacios vacíos que implica una porosidad cerrada. Entre los cristales de calcita sobresale uno de sulfato de bario [1], cuya formación se explica como un producto secundario durante el proceso de enterramiento del friso.

FIGURA 10. Imágenes de microscopio electrónico de barrido (MEB) de las fases del mortero de los relieves (Fotografía: Demetrio Mendoza Anaya, 2002; cortesía: ININ). es de notar que las láminas petrográficas del relieve de la Sub IIC-1 de Calakmul presentan un tipo de textura similar a la correspondiente a los mascarones del sitio arqueológico de Nakbé, San José, Guatemala (Hansen y Rodríguez-Navarro 2002:185).

Una observación pertinente sobre el proceso de cementación del relieve aquí bajo estudio concierne a las Figuras 2 y 3 , donde se aprecia que en el cementante constituido por cristales de micrita también contiene microesparita dispersa y como formación secundaria en la periferia de algunos clastos, material que sirvió para reforzar la cohesión entre partículas. ${ }^{7}$ De acuerdo con Hansen et al. (2008:21), la presencia de microesparita en los morteros de cal suele ser consecuencia de un proceso de cristalización originado en un apagado con poca agua, mismo que propició una mayor carbonatación; ${ }^{8}$ aspecto que se puede relacionar con la preparación de los morteros. Aún hoy en día, albañiles de origen maya con amplia experiencia en el manejo de la cal preparan los morteros de una forma particular: primero mezclan al $\mathrm{CaO}$ con las cargas $y$, posteriormente, agregan agua a la mezcla; es decir, no realizan un apagado inicial con agua, sino que dejan que la cal hidratada forme una masa que pueda aglutinarse formando por carbonatación una costra superficial que retiene la humedad. ${ }^{9}$ Los maestros suelen

\footnotetext{
${ }^{7}$ Sobre la discusión de relación de deterioro y neoformaciones en el estuco, véase Straulino et al. (2013:97).

${ }^{8}$ La re-cristalización también puede haberse producido durante el largo enterramiento del relieve: por más de 2000 años, éste permaneció debajo de otro edificio en condiciones que favorecieron la permanencia de humedad, y en consecuencia, un proceso parcial de disolución. ${ }^{9}$ Esta observación fue realizada durante los trabajos de impermeabilización llevados a cabo en el Templo de Guerreros de Chichén Itzá por el maestro albañil Pedro Dzib Miam (2007) y su equipo de albañiles locales. Este proceso se había registrado ya por la Carnegie Institution of Washington en la década de 1920, durante las labores de restauración del mismo edificio (cfr. Morris et al. 1931:224).
} 
dejar a esta mezcla hidratar por lo menos un par de días; sin embargo, el agua invariablemente resulta insuficiente para que la cal viva $(\mathrm{CaO})$ se transforme por completo en hidróxido de calcio $\left(\mathrm{CaOH}_{2}\right)$.

Adicionalmente, nuestro estudio ha mostrado que otra de las características tecnológicas notables en los morteros del relieve Sub IIC-1 de Calakmul es la presencia de restos de carbón (Figuras 9a y 10c), material que plausiblemente provino de los restos de la madera verde necesaria para la realización de hornos abiertos utilizados en las piras para la quema de cal (Schneider 2002:103). Aunque por lo regular estas inclusiones tienen el mismo tamaño que las cargas, en nuestro caso se llegaron a encontrar fragmentos de hasta $1 \mathrm{~cm}$ (García 2011:225); de hecho, la amplia distribución de fragmentos de carbón en el mortero parece responsable de la coloración grisácea del mortero. Considerando esta evidencia, inferimos que el proceso de apagado de cal debió realizarse a pie de obra, quizá como parte de la producción masiva de cal para edificar el conjunto arquitectónico.

\section{Enlucido}

La capa fina que se distingue en la faz exterior de las muestras de petrografía corresponde al acabado final del relieve (Figura 11), cuya finalidad fue homogeneizar superficie y servir de base al proceso de modelado, a la superposición de planos y a la aplicación de las capas de color.

En la elaboración de cerámica, la aplicación final de una capa líquida de arcilla durante el proceso de modelado permite alisar la superficie (cfr. Caro Bellido 2008:89): un proceso semejante privó en las formas modeladas de relieve de estuco de la Sub IIC-1 cuando éstas aún no habían completado su fraguado. Evidencia de ello se encuentra en la lámina petrográfica de la Figura 11: si bien la capa de enlucido está perfectamente integrada a la matriz de los volúmenes, ésta se distingue por cambios de textura. Adicionalmente, también se observa una pequeña fisura entre capas de enlucido y matriz, misma que

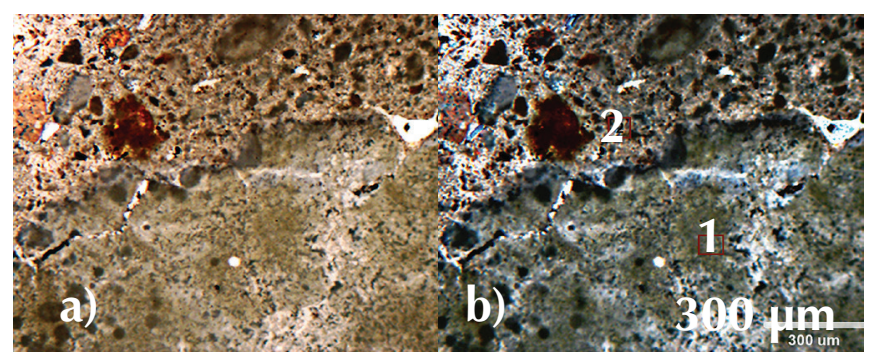

FIGURA 11 Imágenes petrográficas de las capas del sustrato de los relieves: a) luz paralela; b) nicoles cruzados. Se observa claramente la diferencia de textura de la capa de enlucido [1] y la matriz del relleno [2]. Nótese que en la capa del enlucido hay zonas más opacas que otras, lo cual puede interpretarse como la mezcla de micrita con minerales arcillosos. Esta muestra también presenta una micro-fisura en la zona de unión entre capas. (Fotografía: Petroanálisis ${ }^{\circledR}$ e Instituto de Geología UNAM; fuente: García, 2011:233; cortesía: PAC, INAH).

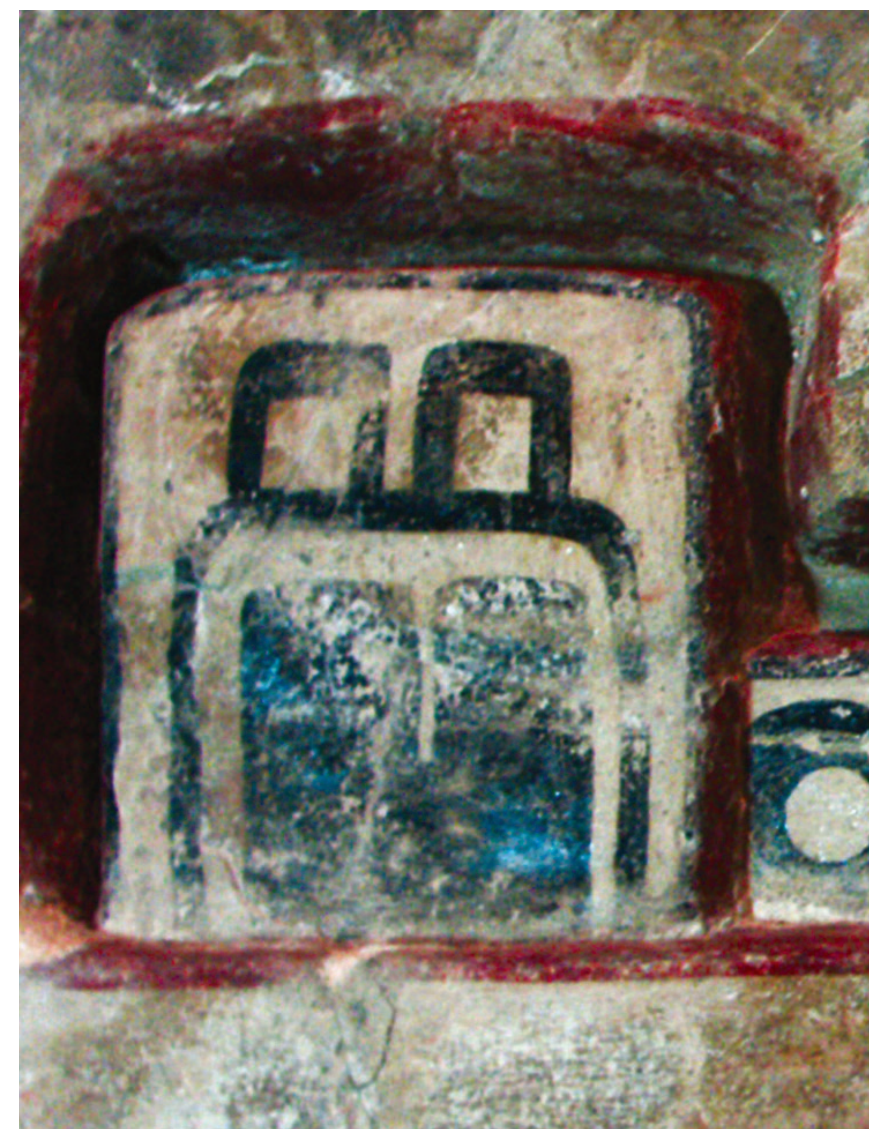

FIGURA 12. Acercamiento del friso modelado en estuco con los tres colores de su paleta (Fotografía: Claudia A. García Solís, 2004; fuente: García, 2011:249, cortesía: INAH).

corrobora que la primera se aplicó posteriormente al modelado y la aplicación de relieves.

Ahora bien, debido a que no hay gran diferencia de composición entre la capa del enlucido y la de la argamasa del relieve, el primero podría derivar del adelgazamiento de pasta de mortero utilizado en la segunda y la adición de partículas arcillosas: efectivamente el análisis por MEB y petrografía muestran un cambio de textura (a granulometría fina) y zonas opacas de arcillas embebidas en la matriz de micrita (Figuras 10 y 11).

\section{Del color en el friso}

Los elementos modelados en el friso de estuco de la Sub IIC-1 presentan, sin excepción, una paleta de tres colores: un amarillo-ocre generalizado, un rojo intenso en fondos y facetas interiores, y el negro para el dibujo caligráfico de diseños (Figura 12). Sin duda, la técnica para la aplicación de los pigmentos fue el temple, lo cual se deduce tanto por la definición de los estratos de color del sustrato como por la apariencia translúcida de los colores. Esta paleta cromática, que es compartida por varios ejemplos de escultura arquitectónica en el Preclásico, como en el Mirador, Nakbé y Holmul, en Guatemala; Acanceh, en Yucatán; Cerros, en 


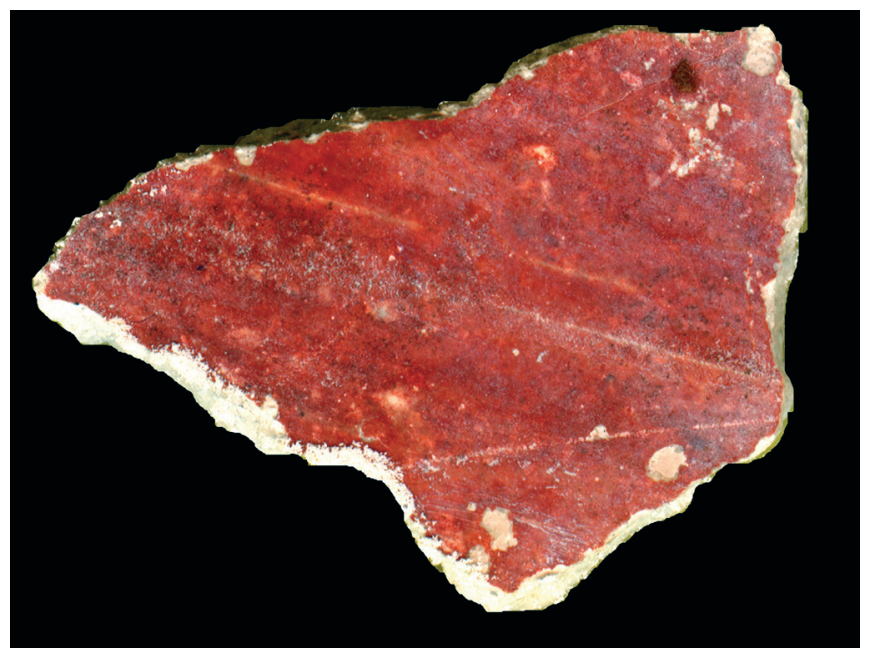

FIGURA 13. Observación macroscópica de muestra de color rojo que corresponde a un fragmento del aplanado del friso bajo estudio. El color rojo no se observa homogéneo porque hay zonas de tonalidad más intensas que otras (MUNSELL ${ }^{\circledR} 10$ R 4/6, 5/6 y 5/8). También se presentan zonas veladas de carbonatos en superficie, aunque algunas franjas blancas corresponden a zonas no cubiertas por el color (Fotografía: Claudia A. García Solís, 2008; fuente: Gacía, 2011:23; cortesía: INAH).

Belice; El Tigre, en Campeche, entre otros casos de la misma temporalidad, se describe a continuación.

\section{Rojo}

El color rojo es el tono más vívido y abundante en el friso que nos ocupa (Figura 13): se empleó tanto en la sinopia como en el fondo o primer aplanado con la finalidad de dar profundidad, al acentuar los volúmenes y los cantos del relieve.

Un aspecto notorio de su aplicación es que no fue homogéneo, resultando zonas más saturadas que otras y, en muchos casos, siguiendo un patrón de líneas (Figura 13). Este efecto quizá se produjo con la superposición, en distintos momentos del proceso de modelado, de capas diluidas de color por medio de algún tipo de brocha, como se discutió en la sección relativa al aplanado.

En los volúmenes de relieve aquí bajo análisis, el color rojo también, se aplicó, es más de una capa, sobre una capa inicial de pintura amarilla: esta superposición de capas coloreadas se refleja en la variabilidad de tonalidades, que van desde una gradiente anaranjada, por la mezcla con el fondo amarillo, hasta una roja de mayor intensidad; al microscopio óptico, este efecto se observa en la variabilidad de grosor del estrato de color (Figura 14).

Cabe señalar que el rojo fue el único color de la paleta cromática del friso que resultó fácilmente identificable mediante diferentes técnicas analíticas: la presencia de hematita como partículas redondeadas, o pigmentos, fue evidente en MEB, EDS y DRX. Asimismo, en las imágenes

FIGURA 14. Análisis de microscopia óptica (MO) de los tres colores del friso (Fotografía: Javier Vázquez Negrete, 2005; cortesía: ENCRYM-INAH).

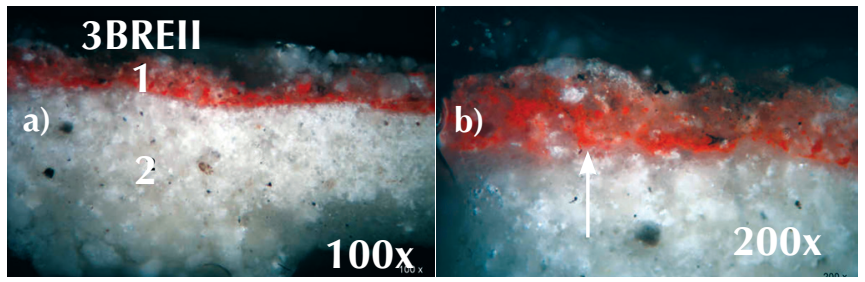

[1] Capa pictórica de color rojo heterogénea pobre en pigmento mezclada con cristales de carbonato de calcio.

[2] Capa de soporte compacto con restos de carbón e inclusiones de fragmentos líticos de tonos ocres.

Capa heterogénea de color sobre un sustrato alisado. La inclusión de los cristales de $\mathrm{CaCO}_{3}$, pudo darse por la mezcla intencional con el pigmento durante su aplicación y por carbonatación parcial del soporte en la capa de color. El tono más saturado por debajo de la capa de color quizás corresponda a la mezcla con el color amarillo de fondo
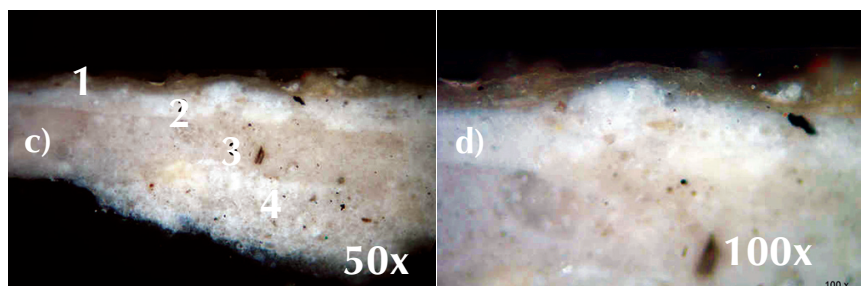

[1] Capa pictórica traslucida de tono amarillo.

[2] Capa de soporte de color blanco de textura fina con restos de carbón.

[3] Capa de soporte blanco rosado concentrado en una capa, textura media con restos de carbón.

Se observa una capa homogénea de color siguiendo el relieve del sustrato de textura fina. La diferencia entre las capas del soporte no está bien definida porque se mezcla con la textura media, aunque si es explícita la diferencia en color y compactación. Existe una buena adherencia entre capas.

[4] Capa de soporte de textura media blanca.

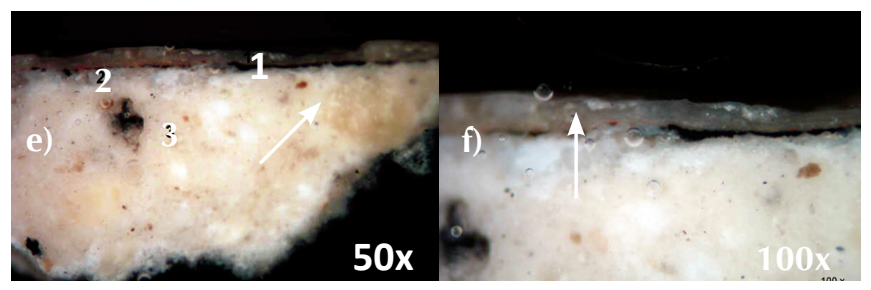

[1] Capa pictórica homogénea de color negro.

[2] Capa de soporte blanquecino compacto de textura fina $y$ color blanco, discontinua por la inclusión de cargas.

[3] Capa de soporte en un blanco rosado de textura media con restos de carbón y clastos de diferentes tamaños.
Soporte alisado y compacto. No hay una división clara entre capas del soporte, aunque debajo de la capa pictórica se aprecia un estrato más fino que el resto del soporte.

Sobre la capa de color negro se observan restos de pigmento rojo, es posible que se hayan quedado atrapados en la capa carbonatada superficial. 
de $\mathrm{MO}$ se detectaron partículas incluidas en la capa de color, a manera de cristales de $\mathrm{CaCO}_{3}$, entre otras impurezas (Figuras 14a y $14 b$ ).

\section{Amarillo}

En el relieve de la Sub IIc-1 se empleó el color amariIlo para iluminar las formas modeladas. Aunque se haya aplicado de manera homogénea, la tonalidad no resulta tan definida, ya que la translucidez de este estrato hace que se difumine con el tono de la matriz del estuco (Figura 14c).

La identificación del amarillo a través de análisis instrumentales no sólo fue complicada, sino que no se lograron resultados concluyentes para elaborar una interpretación. La observación en MO (Figuras 14c y 14d) reveló que esta capa de color posee poco grosor y una apariencia traslúcida con algunos puntos dispersos de color anaranjado que no son tan evidentes; aunado a ello, cuando el color rojo está superpuesto, como se observa en la Figura $14 \mathrm{~b}$, la capa amarilla no alcanza a diferenciarse. De hecho, no es posible afirmar que partículas coloreadas en amarillo hubiesen sido utilizadas como pigmentos, ya que, además de no tener una estructura definida, los puntos dispersos no parecen haber formado conglomerados ex profeso para saturar el tono del color. En el análisis por MEB (Figura 15b) se ratifica que la capa de color amarillo es sumamente delgada $(0.05 \mathrm{~mm})$ y que aglomera partículas redondeadas de textura fina con poco poder cubriente. En las zonas de mayor concentración se evidencian líneas paralelas que tal vez correspondan con las cerdas del pincel, o brocha, utilizado para la aplicación del color (Figura 15b). El análisis por medio de EDS fue el único que arrojó la identificación de Fe en ese color, una alusión a la posibilidad de limonita (Figura 15f); sin embargo, comparando el porcentaje de $0.4 \%$ de Fe del color amarillo, con la diferencia de $6.18 \%$ del mismo elemento en el color rojo, no consideramos un resultado concluyente. $^{10}$

Con el fin de obtener más información sobre la capa de color amarillo, se realizó un mapeo químico, en un corte tangencial, de dicha capa, lo que hizo posible diferenciar las agrupaciones minerales de los elementos previamente determinados en el sustrato y la capa de color (véase García 2011:248). Uno de los patrones interesantes a resaltar fueron las coincidencias de sílice y aluminio de algunas áreas, por lo que podríamos suponer la presencia de arcillas, como se identificaron por medio de DRX en la capa de color rojo.

Con estos datos dejamos abierta la posibilidad de que este color amarillo se trate de un material de origen orgánico fijado en una capa de arcilla, como ya se ha sugeri-

\footnotetext{
${ }^{10}$ El doctor Demetrio Mendoza Anaya, del Instituto Nacional de Investigaciones Nucleares (ININ), opina que, a pesar de esta mínima diferencia, el color amarillo podría producirse por la presencia de óxidos de hierro.
}

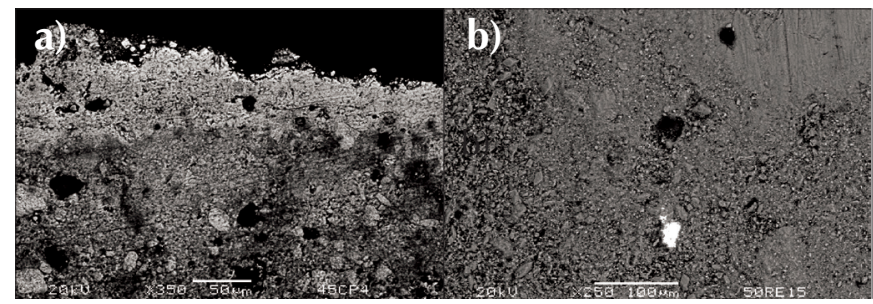

La muestra 45 CP4 vista por MEB se distingue como una capa de material más fino, cuya composición, por medio de microanálisis, no varió de la capa del enlucido ni del soporte.
En toma tangencial de la 50RE15 (imagen derecha) se observa la textura fina de la capa amarilla dada por partículas redondeadas entre microcristales de calcita. También se distingue una capa menos porosa que quizás corresponda a una zona de mayor concentración de color. En esta capa se aprecian estrías paralelas.

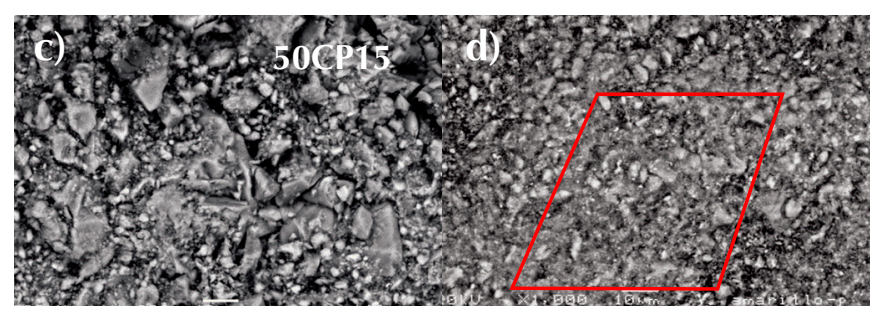

e)

f)
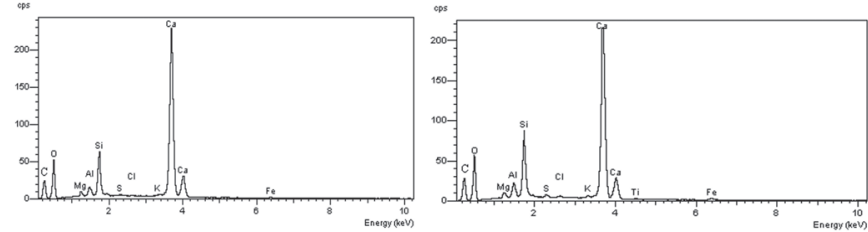

Estas dos imágenes corresponden a acercamientos tangenciales: sustrato, en la toma izquierda y la capa de color, a la derecha. La diferencia más notable consiste en la disminución del tamaño de las partículas en la capa de color, lo que podría corresponder al enlucido, porque tiene una estructura similar al sustrato. Sin embargo, también se aprecia un material continuo que hace que las partículas se vean más unidas. Se aprecia un ligero pico de Fe que Ilega a notarse ligeramente en la capa pictórica.

FIGURA 15. Estudios de microscopia electrónica de barrido acoplada con espectroscopía de rayos X por energía dispersiva (MEB-EDS) de muestras de la sección del soporte y la capa pictórica amarilla con gráficas de análisis elementales (Fotografía: Demetrio Mendoza Anaya; cortesía: ININ).

do anteriormente en ejemplos de pintura mural (cfr. Magaloni 2001:181; Vázquez de Agredos 2006) y en Nakbé, donde se llegó a identificar el colorante (cfr. Hansen et al. 1995). Las similitudes de la apariencia translúcida, visible en el corte de MO, y la presencia de arcillas, registrada en el mapeo del microanálisis con EDS, serían dos líneas de investigación que tendrían que estudiarse con mayor profundidad para corroborar si este sustrato de color tiene un origen orgánico. 
Negro

El color negro fue el menos utilizado en la composición del friso de la Sub IIC-1 de Calakmul, se reservó para el trazo de diseños que otorgaron mayor significado a las formas modeladas (Figuras 14e y 14f).

En la paleta maya, la mayoría de los colores negros proviene de la quema deliberada de huesos o restos orgánicos, aunque también existen otros de origen mineral (Magaloni 2001:181). Concretamente en el caso que nos ocupa, el color negro empleado en los trazos del relieve es producto del molido fino de carbón (Figura 15e), lo cual fue confirmado por los análisis elementales que detectaron un alza considerable en el pico de carbono (cfr. García 2011:252).

\section{Consideraciones finales}

En los sitios de la cuenca del Mirador, el salto tecnológico cuantitativo entre los someros acabados de inicios del Preclásico Medio y la innovación implícita, a partir del 600 a. C., en la elaboración de las sofisticadas representaciones iconográficas modeladas en estuco estuvo acompañado por un proceso de consolidación sociopolítico en la región del Petén, hoy Guatemala (cfr. Hansen y Rodríguez-Navarro 2002). El estudio tecnológico aquí presentado sobre el relieve de la Sub IIC-1 de Calakmul sugiere que este sitio, junto con el de Nakbé y el Mirador, se integró a esta dinámica regional a través de la adaptación tecnológica a su paisaje natural, por un lado, y al conocimiento de técnicas para dotar de significados a la nueva arquitectura monumental, por el otro.

Con respecto a los relieves de estuco de Nakbé y el Mirador, el friso que aquí nos ocupa no sólo comparte características formales - tales como la masividad en su representación y la aplicación de la paleta cromática restringida al rojo, amarillo y negro-, sino que también muestra importantes analogías en cuanto a propiedades materiales, incluyendo la textura de las argamasas de cal y el aspecto translúcido del amarillo derivado, tal vez, del empleo de colorantes. Aunque las técnicas instrumentales utilizadas no permitieron identificar con certeza la composición del color amarillo, aquí se ha planteado una primera hipótesis que apunta al uso de óxidos de hierro, aunque también se admite la posible relación del uso de arcillas como base de algún tinte orgánico, ambas ideas deben corroborarse.

Adicionalmente, los análisis especializados empleados por esta investigación han trazado la pauta para identificar más puntualmente los componentes de los materiales arqueológicos y su configuración. Entre las técnicas analíticas empleadas, la petrografía aparece como una herramienta especialmente útil para los estudios de técnica de manufactura de los elementos modelados en estuco, ya que permite, además de observar estructuras cristalinas y su integración en los morteros de cal, generar referentes de comparación. El establecer tipologías basadas en la simple morfología de sus cargas y su relación con la matriz de un mortero resulta una vía de comparación objetiva.

El uso de varias técnicas analíticas durante la investigación dio la posibilidad de corroborar y/o complementar los resultados de los diferentes estratos, que representan estadios de la secuencia operativa. Las observaciones macroscópicas, sin embargo, constituyen una referencia indispensable para la interpretación de los resultados. Gracias a que el registro y análisis de técnica se inició desde el proceso de excavación, se identificaron todos los componentes del friso (García 2009); de lo contrario no se tendría más que una visión parcial del proceso tecnológico. Si bien el estudio de técnica del friso de Calakmul se enfocó en la identificación de los procesos, más que en el análisis material, la información que se presenta en esta contribución sustenta la idea de que la gran dureza y consistencia de los relieves, y la obtención de voluminosos estratos de más de $10 \mathrm{~cm}$ de grosor sin previa capa de preparación, fueron resultado de la especialización y habilidad que distinguen a los elementos modelados en estuco del Preclásico por los mayas. El condicionamiento del paisaje natural del Petén implicó un uso racional y un claro conocimiento de los materiales de la región, así como una alta especialización en técnicas, y no de las cualidades otorgadas por un material en específico (cfr. Villaseñor 2008; Gillot 2014). De la misma forma que se considera que la visión macroscópica debe ser la guía de la interpretación de los microanálisis en general, la interpretación de ciertos materiales también requiere de una corroboración arqueológica en cuanto a la identificación y accesibilidad de fuentes de materia prima.

Para finalizar, vale subrayar que el estudio de la materialidad no sólo es útil para acercarnos a la complejidad social del proceso de manufactura del friso de la Sub IIC-1 sino también para tener un análisis completo de sus fases tecnológicas, aspectos que adicionalmente nos ayudan a entender su comportamiento en las condiciones en las que se encuentra actualmente expuesto y, así, a asegurar su conservación.

\section{Agradecimientos}

Nuestra gratitud al arqueólogo Ramón Carrasco quien permitió la investigación (y conservación) del friso de la Sub IIC-1, y al maravilloso equipo del proyecto, que brindó todo su apoyo: Omar Rodríguez, Agustín Anaya y María Inés Colón. Merece reconocimiento el Centro de Investigación y de Estudios Avanzados del Instituto Politécnico Nacional (Cinvestav-Mérida, IPN) por tener las puertas siempre abiertas, y especialmente, el maestro en ciencias Daniel Aguilar, por realizar los análisis de DRX. Nuestro agradecimiento también a: Petroanálisis ${ }^{\odot}$ por el apoyo en la elaboración del estudio petrográfico; al doctor Víctor Dávila, del Departamento de Geología de la 
Universidad Nacional Autónoma de México (DG-UNAM, México), por sus muy pertinentes observaciones; al ingeniero Alberto Sulub, de la Facultad de Ingeniería de la Universidad Autónoma de Yucatán (FI-UAdY), por los análisis físicos y mecánicos, y, finalmente, al químico Javier Vázquez, del Laboratorio de Enseñanza de la Escuela Nacional de Conservación y Restauración (LE-ENCRyM) del Instituto Nacional de Antropología e Historia (INAH, México), por su ayuda con las láminas de MO y su asesoría. Parte de esta investigación fue financiada por el Programa de Posgrados de Excelencia del CONACYT (2002-2004).

\section{Referencias}

\section{Barrera Vásquez, Alfredo}

1980 Diccionario Maya Cordemex, Editorial Cordemex, Mérida.

Boyton, Robert S.

1966 Chemistry and Technology of Lime and Limestone, Nueva York, Interscience Publishers-John Wiley \& Sons.

Braswell, Geoffrey 2003 The Maya and Teotihuacan: Reinterpreting Early Classic Interaction, Austin, University of Texas Press.

Caro Bellido, Antonio 2008 Diccionario de términos cerámicos y de alfarería, Cádiz, Agrija Ediciones.

Carrasco Vargas, Ramón 2005 "The Sacred Mountain: Preclassic Architecture in Calakmul", en Lords of Creation: the Origins of Sacred Maya Kingship, Virgina Fields \& Dorie Reents-Budet y Ricardo Argucia (eds.), Los Angeles, Scala, 62-66.

Carrasco, Ramón y María Inés Colón 2005 "El reino de Kaan y la antigua ciudad de Calakmul", Arqueología Mexicana, 13 (75):40-47.

Castro-Mora, José (comp.)

2002 Monografía geológico-minera del estado de Campeche, México, Consejo de Recursos Minerales-Secretaría de Economía.

Dobres, Marcia-Anne

2000 Technology and Social Agency: Outlining a Practice Framework for Archaeology, Oxford, Blackwell.

Duch-Gary, Jorge

1991 Fisiografía del estado de Yucatán, México, UAdY.

Dzib Miam, Pedro

2007 Comunicación personal, entrevista realizada en la Zona Arqueológica de Chichén Itzá, diciembre de 2007.

García Solís, Claudia A.

2009 "El friso modelado en estuco de la Sub IIC-1 de Calakmul. Una propuesta de conservación basada en la interpretación de su deterioro a través de su historia cultural", en Luis Fernando Guerrero (coord.), Conservación de bienes culturales: acciones y reflexiones, México, INAH.

2011 "Tecnología de la escultura arquitectónica modelada en estuco de la Sub IIC-1: implicaciones sociales para el Preclásico en Calakmul", tesis de maestría en antropología opción arqueología, Mérida, UAdY.
García Solís, Claudia A. y Berenice Valencia Pulido 1997 "El deterioro de piedra en la Zona Arqueológica de Chicanná, Campeche, y una propuesta para su conservación", tesis de licenciatura en conservación-restauración de bienes muebles, México, ENCRyM-INAH.

García Solís, Claudia A. y Yareli Jáidar Benavides 2013 "El uso de aditivos orgánicos en mezclas de morteros de cal en el área maya", en Luis Barba Pingarrón e Isabel Villaseñor Alonso (eds.), La cal, propiedades y usos, MéxiCO, UNAM/Asociación Nacional Fabricantes de Cal.

García Solís, Claudia A., Patricia Quintana Owen y Francisco Bautista-Zúñiga

2006 "La identificación de materiales arcillosos y pétreos utilizados en la manufactura del friso modelado en estuco de la Sub IIC-1 de Calakmul, a través de análisis de difracción de rayos X", en Demetrio Mendoza Anaya, Jesús Arenas Alatorre, V. Rodríguez y José Luis Ruvalcaba-Sil (eds.), La ciencia de materiales y su impacto en arqueología, Puebla, Academia Mexicana de la Ciencia, III:237-252.

Geovannini Acuña, Helga

2008 Rain Harvesting in the Rainforest: The Ancient Maya Agricultural Landscape of Calakmul, Campeche, Mexico, Oxford, BAR International.

Greene, Merle

1987 The Sculpture of Palenque, Nueva Jersey, Princeton University Press, III.

Gillot, Céline

2014 "The Use of Pozzolanic Materials in Maya Mortars: new Evidence from Río Bec (Campeche, México)", Journal of Archaeological Science, 47:1-9.

Hansen, Eric y Carlos Rodríguez-Navarro

2002 "Los comienzos de la tecnología de la cal en el mundo maya: innovación y continuidad desde el Preclásico Medio hasta el Clásico Tardío en Nakbé, Petén, Guatemala", en J. P. Laporte, H. L. Escobedo y B. Arroyo (eds.), XV Simposio de Investigaciones Arqueológicas en Guatemala, Guatemala, Museo Nacional de Arqueología y Etnología, 183-187.

Hansen, Eric, Richard D. Hansen y Michele F. Derrick 1995 “Los análisis de los estucos y pinturas arquitectónicas de Nakbé: resultados preliminares de los estudios de los métodos y materiales de producción", en J. P. Laporte y $\mathrm{H}$. L. Escobedo (eds.), VII Simposio de Investigaciones Arqueológicas de Guatemala, Guatemala, Museo Nacional de Arqueología y Etnología, 543-560.

Hansen, Eric, Carlos Rodríguez-Navarro y K. Van Balen 2008 "Lime Putties and Mortars: Insights into Fundamental Properties", Studies in Conservation, 53:9-23.

Ingold, Tim

2001 "Beyond art and Technology: the Anthropology of Skill", en Michael B. Schiffer (ed.), Antropological Perspectives on Technology, Albuquerque, University of New Mexico Press.

Leroi-Gourhan, André

1964 Le geste et la parole I: technique et langage, París, Albin Michel. 
Littman, Edwin

1958 Ancient Mesoamerican Mortars, Plasters and Stuccos:

Composition and Origin of Sascab, American Antiquity, 24

(2):172-176.

Magaloni, Diana

1996 "El espacio pictórico teotihuacano: tradición y técni-

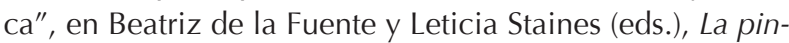
tura mural prehispánica en México I. Teotihuacan, México, IIE-UNAM, II:187-225.

2001 "Materiales y técnicas de la pintura mural maya", en B. de la Fuente y L. Staines (eds.), La pintura mural prehispánica en México II, Área Maya, México, IIE-UNAM, III:155-198.

Mateos González, Frida

1997 Toniná: la pintura mural y los relieves. Técnicas de manufactura, México, INAH.

Mora, Paolo, Laura Mora y Paul Philippot

1984 Conservation of Wall Paintings, Londres, Butterworth/ ICCROM.

Morris, Earl H., Jean Charlot y Ann Axtell Morris 1931 The Temple of the Warriors at Chichen Itzá, Yucatan, Washington, Carnegie Institution of Washington, 406:2.

Oates, J. A. H. 1998 Lime and Limestone. Chemistry and Technology, Production and Uses, Weinheim/Alemania, Wiley-VCH.

Pelegrin, J., C. Karlin y P. Bodu

1988 "Chaînes opératoires': un outil pour le préhistorien", en J. Tixier (ed.), Téchnologie préhistorique, Notes et Monographies Techniques, París, CNRS, 25:55-62.

Rodríguez Campero, Omar

2008 La arquitectura Petén en Calakmul: una comparación regional, documento electrónico disponible en [http:// www.famsi.org/reports/02070es/02070esRodriguezCampe ro01.pdf], consultado en marzo del 2016.

Schiffer, Michael B.

2004 Technological Perspectives on Behavioural Change. Culture and Technology Series, Tucson, The University of Arizona Press.

Schneider, T. C.

2002 "Traditional Maya Lime Production: Environmental and Cultural Implications of a Native American Technology", tesis de doctorado en arquitectura, Berkeley, UC.

Straulino, Luisa, Sergey Sedov, Dominique Michelet y Sandra Balanzario

2013 "Weathering of Carbonate Materials in Ancient Maya Constructions (Río Bec and Dzibanché): Limestone and Stucco Deterioration Patterns", Quaternary International, 315:87-100.

Vargas Ramos, Mónica

2007 "Hidróxido de bario. Una evaluación para su utilización como consolidante de estucos", tesis de licenciatura en conservación-restauración de bienes muebles, México, ENCRYM-INAH.

Vázquez del Mercado, Ximena y A. Mercedes Villegas

1993 "Los estucos modelados del Palacio y del Templo de las Inscripciones de Palenque: una metodología de análisis para la técnica de manufactura", tesis de licenciatura en restauración de bienes muebles, México, ENCRyM-INAH.

Vázquez de Agredos, María Luisa

2006 "Recursos materiales y técnicas pictóricas en los murales de las Tierras Bajas Mayas", tesis de doctorado en historia del arte, Valencia, uv.

Villaseñor Alonso, María Isabel

2008 "Lowland Maya Lime Plaster Technology: A Diachronic Approach", tesis de doctorado en arqueología, Londres, ULC.

2010 Building Materials of the Ancient Maya. A Study of Archaeological Plasters, Saarbrücken, Lamber Academic Publishing.

Zetina Ocaña, Sandra

2007 "Análisis de la técnica de manufactura de los mascarones de estuco del Edificio A-1 y B-4 de Kohunlich, Quintana Roo", tesis de licenciatura en conservación-restauración de bienes muebles, México, ENCRYM-INAH.

\section{Síntesis curricular del/los autor/es}

\section{Claudia A. García Solís}

Universidad Autónoma de Yucatán (UADY), México clausoldia@gmail.com

Licenciada en restauración de bienes muebles (Escuela Nacional de Conservación, Restauración y Museografía [ENCRyM], Instituto Nacional de Antropología e Historia [INAH], México) y maestra en arqueología (Universidad Autónoma de Yucatán [UAdY], México). Con más de 15 años de trayectoria profesional en la gestión, conservación e investigación, enfocada principalmente en pintura mural y escultura arquitectónica del área maya. En 2011 recibió el Premio INAH Paul Coremans por su proyecto de conservación de Mayapán, Yucatán, México. Conservadora adscrita al Centro INAH-Yucatán, actualmente realiza estudios de doctorado en La Trobe University (La Trobe), Melbourne, Australia, sobre el tema de políticas y gestión de patrimonio arqueológico.

\section{Patricia Quintana Owen}

Centro de Investigación y de Estudios Avanzados (Cinvestav), Instituto Politécnico Nacional (IPN), Mérida, Yucatán, México pquint@cinvestav.mx

Doctora en química inorgánica (cerámica) (Universidad Nacional Autónoma de México [UNAM], México). Responsable del Laboratorio Nacional de Nano y Biomateriales (LANNBIO), con más de 35 años de trayectoria en la investigación en diversas áreas de la química y la caracterización de materiales cerámicos con propiedades eléctricas, en biomateriales, arqueológicos y síntesis de recubrimientos como sistemas de protección contra el deterioro de rocas calcáreas. Es investigadora del Departamento de Física Aplicada del Centro de Investigación y de Estudios Avanzados, (Cinvestav, Unidad Mérida, Yucatán, México), del Instituto Politécnico Nacional (IPN), México. Es miembro del Sistema Nacional de Investigadores (SNI, México), nivel III, así como de la Academia Mexicana de Ciencias. 


\section{Demetrio Mendoza Anaya}

Instituto de Investigaciones Nucleares (ININ),

Secretaría de Energía (SENER), México

demetrio.mendoza@inin.gob.mx

Licenciado en física (Facultad de Ciencias [FC], Universidad Nacional Autónoma de México [UNAM], México). Doctor en ingeniería de materiales (Universidad Autónoma de Querétaro [UAQ], México). Desde hace 20 años labora como investigador en el Instituto Nacional de Investigaciones Nucleares (ININ), donde ha participado y coordinado diversos proyectos de investigación, principalmente relacionados con la síntesis de materiales y su caracterización por diferentes técnicas nucleares y convencionales como microscopia electrónica y difracción de rayos X. Ha adquirido experiencia en arqueometría aplicando técnicas analíticas en el estudio de materiales de origen arqueológico; ha publicado más de 30 artículos en revistas indexadas, ha contribuido en la formación de recursos humanos y ha participado en diferentes congresos nacionales e internacionales, varios de éstos en el área de arqueometría. Es miembro del Sistema Nacional de Investigadores (SNI, México), nivel II.

Postulado/Submitted 12.10.15

Aceptado/Accepted 05.04.16

Publicado/Published 11.07.16 